\title{
Microstructure and Microanalysis of Metal Artifacts from Kerkenes Dağ, Central Turkey, ca. 600 B.C.
}

\author{
J.W. Lehner,* S. Prikhodko ** \\ * Cotsen Institute of Archaeology, University of California - Los Angeles, Los Angeles, CA 90095 \\ ** Department of Materials Science and Engineering, University of California - Los Angeles, Los \\ Angeles, CA 90095
}

Metal technology during the Iron Age in Central Turkey, ca. 1200 - 333 B.C., witnessed several key innovations in production and use that influenced society at that time [1]. Lesser known innovations during this time period occur in the tradition of bronze metallurgy. The excellent preservation of bronze metal found in a destroyed palatial context at the archaeological site of Kerkenes Dağ in central Turkey provides central clues into the development of bronze technology.

This paper explores the microstructure and composition of several non-ferrous metal artifacts from excavated contexts in order to ascertain how these objects were produced and used. An important capability of the variable pressure (VP) SEM is that archaeological artifacts can be analyzed nondestructively without modification of their structure and chemistry. Our approach here was to assess microstructure and microchemistry of the samples non destructively by VPSEM coupled with energy dispersive $\mathrm{x}$-ray spectrometry (EDS) and perform high-resolution inductively coupled plasma mass spectrometry (ICP-MS) on the same samples later on.

For the purposes of this paper, we prepared artifact samples for three different analyses. 1.) Samples were mounted, polished and etched for microstrucural analysis with the aid of light optical microscopy; 2.) Mounted samples were analyzed for microstructure and composition using VPSEM and EDS; and 3.) Samples were analyzed by high-resolution ICP-MS for stable lead isotopes to infer base metal provenance.

Results indicate a wide variety of non-ferrous metal technology, using metals from both local and far resource areas. Some objects, including a highly stylized tin bronze sheet cut into the shape of an ibex, appear to be surface treated with tin so as to physically alter the presence of the object. This is one of the earliest examples of bronze surface treatment using tin [2]. The results provide conclusive evidence for highly specialized metal production during this historically unknown period and geographical region [3].

\section{References}

[1] K.A.Yener, E.Geçkinli, H.Özbal, in Archaeometry 94: The Proceedings of the 29th International Symposium on Archaeometry, Ş. Demirci, A. M. Özer, G. D. Summers, Eds. (Ankara, 1996). [2].S.La Niece, P.T.Craddock, Eds., Metal Plating and Patination: Cultural, Technical, and Historical Developments, (Oxford and Boston, 1993).

[3]. This research was funded by the generous support of the Kerkenes Dağ Project, The Laboratory for Molecular and Nano Archaeology (UCLA), The Institute for Integrated Research in Materials, Environments and Society (CSLB), The Institute for Social Research (UCLA), and the Cotsen Institute of Archaeology (UCLA). 


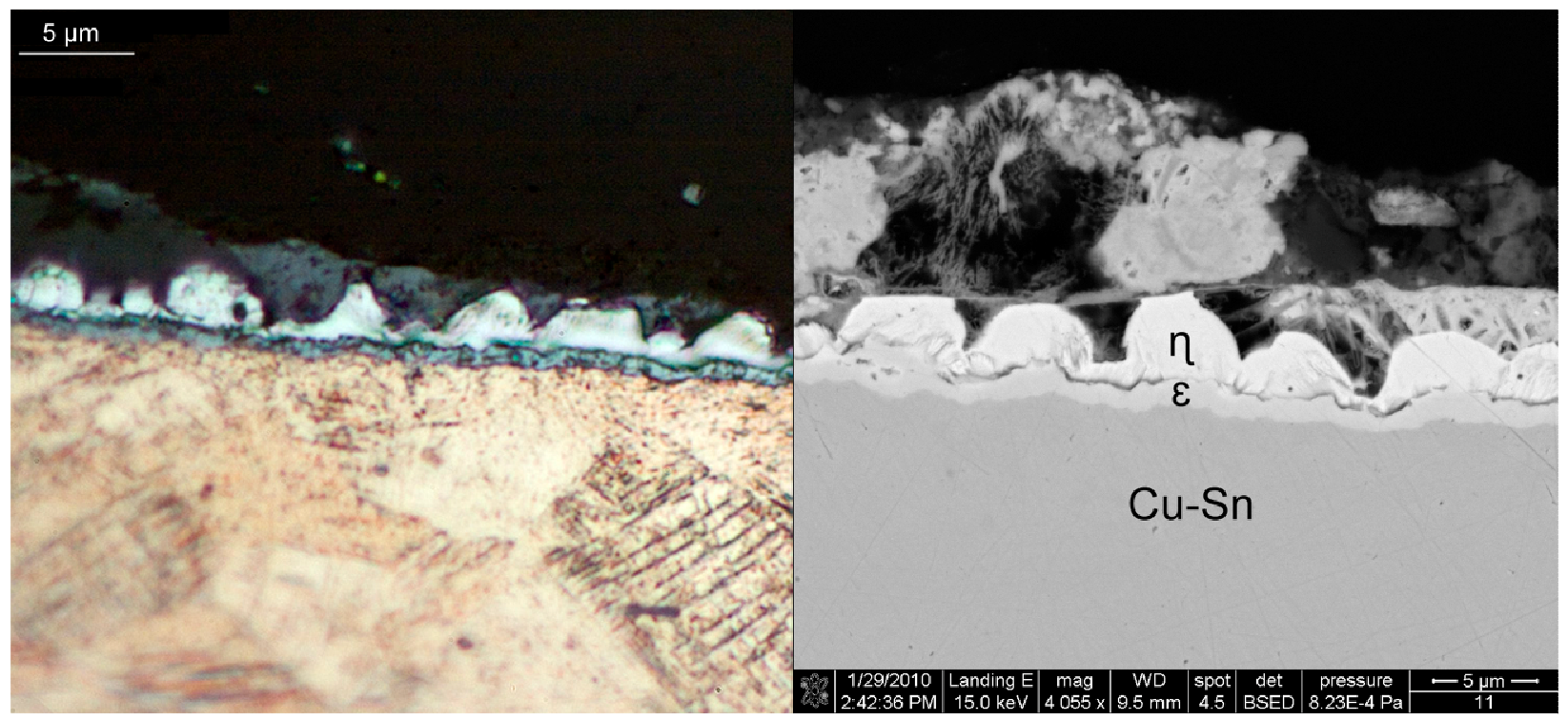

(a)

(b)

Figure 1: Imaging of tin bronze sheet metal artifact from Kerkenes Dag. (a) Optical light microscope image of metallographic section, etched. (b) VPSEM backscattered electron image of the same sample indicating major phases, including tin eta-phase and epsilonphase.

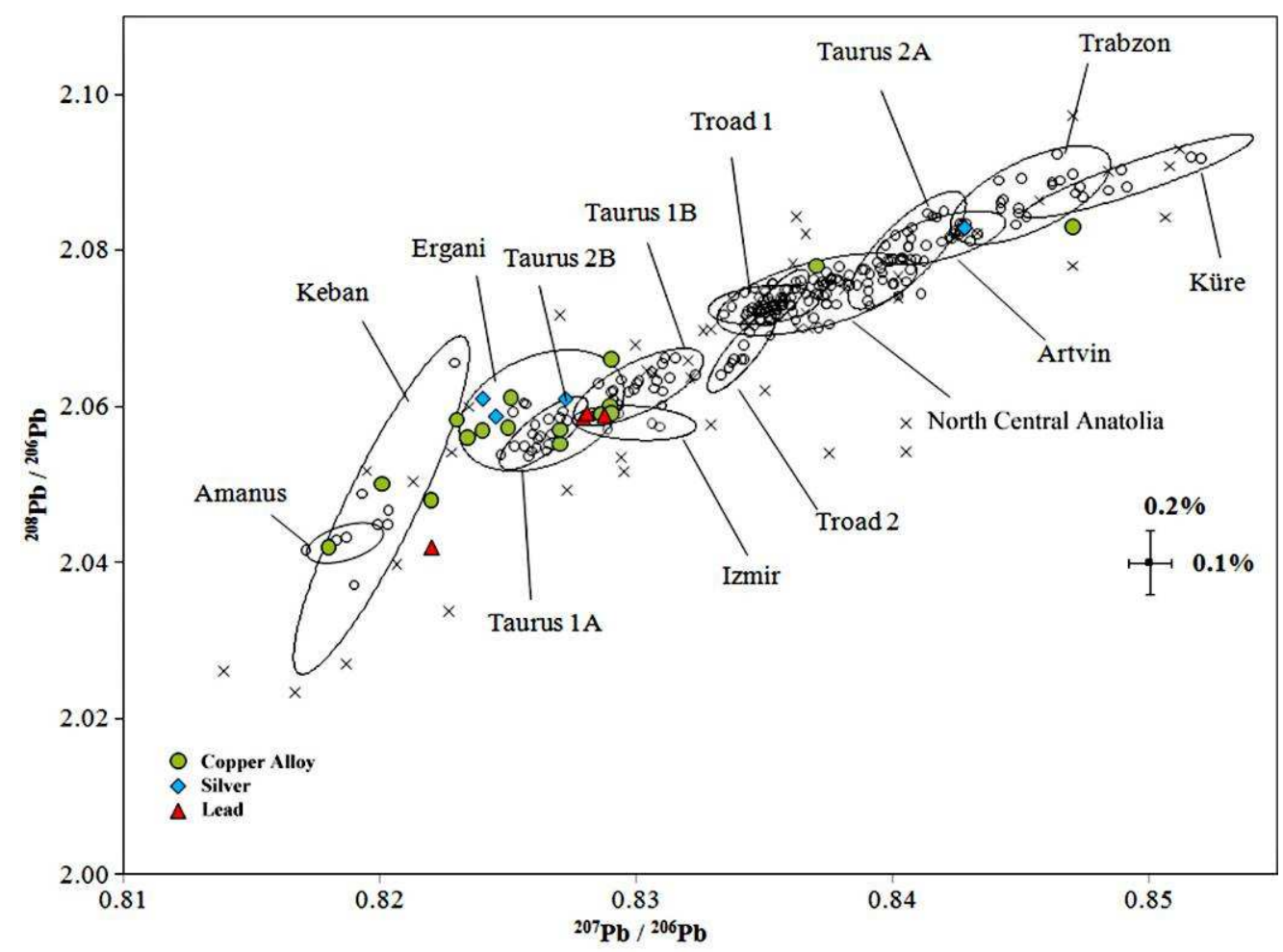

Figure 2: Lead isotope ratio plot showing known ore groupings overlaid by analyzed artifacts from Kerkenes Dağ. 